\title{
26518 - COMPARISON OF PATIENT CONTROLLED EPIDURAL ANALGESIA WITH AUTOMATED SYNCHRONIZED INTERMITTENT MANDATORY BOLUSES FOR LABOR ANALGESIA
}

\author{
Cecilia E. Ocampo MD, Alex T Sia, MMed; Yvonne Lim, MMed; \\ KK Women's And Children's Hosptial, Singapore, Singapore, Singapore
}

INTRODUCTION: The use of continual intermittent boluses (CIB) to maintain labor epidural analgesia has been shown to prolong the duration of analgesia and reduce the incidence of breakthrough pain when compared with a continuous epidural infusion. (1, 2) The use of parturient controlled epidural analgesia (PCEA) with a basal infusion has been shown to reduce pain scores when compared with PCEA without basal infusion in the laboring women. (3) We compared a novel approach of providing basal intermittent boluses in synchrony with PCEA (called Automated Synchronized Intermittent Mandatory Boluses or ASIMB) with PCEA + basal infusion.

METHODS: After hospital ethics committee approval and informed consent, we randomized 42 healthy parturients in early labor to receive $0.1 \%$ ropivacaine + fentanyl 2 microg/ml either via PCEA ( $\mathrm{n}=21$, bolus $5 \mathrm{ml}$, lockout $10 \mathrm{~min}$, basal infusion $5 \mathrm{ml} / \mathrm{H}$ ) or ASIMB ( $\mathrm{n}=21$, patient activated bolus of $5 \mathrm{ml}$, lockout $10 \mathrm{~min}$, basal automated boluses of $5 \mathrm{ml}$ ) after successful induction of combined spinal epidural analgesia (CSEA) with intrathecal ropivacaine $2 \mathrm{mg}+$ fentanyl 15 microg. We hypothesized that ASIMB would be a more efficient technique. The sample size was computed to detect a $20 \%$ reduction in local anesthetic consumption compared with PCEA (á;: 0.05, â;: 0.2).

RESULTS: Even though there was no significant difference in the anthropometric and preanalgesic data between the two groups, there was reduction in the hourly consumption of ropivacaine with ASIMB (median: $5.7 \mathrm{mg} / \mathrm{H}$, range 3.6-20 vs. median: 7.1, 5-12 for PCEA, $p=0.01)$ A higher proportion of parturients in ASIMB did not self bolus (6/21 vs. $1 / 21$ in PCEA, $p=0.03$ ). The time to the first self bolus after CSE was also longer in ASIMB (mean survival time 315 min vs. 190 min in PCEA group, $p=0.04$ by log rank test). There was no difference in pain scores or side effects.

DISCUSSION: ASIMB is a good alternative to PCEA+basal infusion in maintaining labor epidural analgesia

\section{REFERENCES:}

1. Int J Obstet Anesth 2005; 14:305-9.

2. Can J Anesth 2004; 6:581-5.

3. Anaesth Intensive Care 2005; 33:452-6. 